\title{
Ocorrência de raiva em ovinos no Rio Grande do Sul ${ }^{1}$
}

\author{
Daniel R. Rissi², Felipe Pierezan², Glaucia D. Kommers ${ }^{3}$ e Claudio S.L. Barros ${ }^{3}$ \\ ABSTRACT.- Rissi D.R., Pierezan F., Kommers G.D. \& Barros C.S.L. 2008. [Occurrence \\ of rabies in sheep in Rio Grande do Sul, Brazil.] Ocorrência de raiva em ovinos no Rio \\ Grande do Sul. Pesquisa Veterinária Brasileira 28(10):495-500. Departamento de \\ Patologia, Universidade Federal de Santa Maria, 97105-900 Santa Maria, RS, Brazil. E- \\ mail: claudioslbarros@uol.com.br \\ Cases of rabies in sheep occurring in November 2003, in central Rio Grande do Sul \\ state, Brazil, are described. A 3-month-old male, and a 2.5-month-old female sheep were \\ affected. Clinical signs were characterized by abnormal gait, trembling, lateral recumbency, \\ convulsion, opisthotonus, and fever. Histological findings included a non-suppurative \\ myelomeningoencephalitis associated with intracytoplasmic eosinophilic inclusion (Negri) \\ bodies in neurons. Lesions were predominantly observed in gray matter of the spinal cord, \\ brainstem and cerebellum. There was non-suppurative Gasserian ganglionitis in one sheep \\ in which this structure was examined. Immunohistochemistry using rabies virus \\ ribonucleoprotein polyclonal antibody yelded positive result in brain tissue from both sheep. \\ The cases herein reported occurred concomitantly to an outbreak of bat transmitted rabies \\ in cattle in the same region and were considered, on epidemiological basis, to be transmitted \\ by bats, as occurs in endemic bovine rabies in Rio Grande do Sul.
}

INDEX TERMS: Lyssavirus, Rhabdoviridae, rabies, diseases of sheep, immunohistochemistry, neuropathology.

RESUMO.- Descreve-se a ocorrência de raiva em ovinos na região Central do Rio Grande do Sul em novembro de 2003. Foram afetados dois ovinos de raça mista, um macho de três meses e uma fêmea de 2,5 anos de idade que apresentaram sinais clínicos com evolução de cinco dias e caracterizados por dificuldade de locomoção, tremores musculares, decúbito lateral, convulsões, opistótono e febre. Histologicamente havia mielomeningoencefalite não-supurativa, associada a inclusões eosinofílicas intracitoplasmáticas (corpúsculos de Negri) em neurônios nos dois ovinos afetados. Em um ovino em que o gânglio de Gasser foi examinado, havia ganglionite nãosupurativa. As lesões concentravam-se predominante-

\footnotetext{
${ }^{1}$ Recebido em 16 de abril de 2008.

Aceito para publicação em 28 de maio de 2008.

Trabalho inteiramente financiado com verba de projeto Universal do CNPq (Proc.478779/2007-0), e é parte da Tese de Doutorado do primeiro autor, bolsista SWE do CNPq (Proc.202120/2007-4).

${ }^{2}$ Programa de Pós-Graduação em Medicina Veterinária, área de concentração em Patologia Veterinária, Centro de Ciências Rurais, Universidade Federal de Santa Maria (UFSM).

${ }^{3}$ Departamento de Patologia, UFSM, 97105-900, Santa Maria, RS. *Autor para correspondência: claudioslbarros@uol.com.br
}

mente na substância cinzenta da medula espinhal, no tronco encefálico e no cerebelo. Antígeno viral foi detectado em seções selecionadas de ponte e bulbo submetidas ao teste de imuno-histoquímica utilizando anticorpo policlonal anti-ribonucleoproteína do vírus da raiva. Os casos ocorreram em meio a um surto de raiva bovina transmitida por morcegos e foram considerados, com bases epidemiológicas, como transmitidos da mesma forma, como ocorre na raiva endêmica de bovinos no Rio Grande do Sul.

TERMOS DE INDEXAÇÃO: Lyssavirus, Rhabdoviridae, raiva, doenças de ovinos, imuno-histoquímica, neuropatologia.

\section{INTRODUÇÃO}

A raiva é uma doença quase invariavelmente fatal que afeta várias espécies animais. É causada por um vírus da família Rhabdoviridae, gênero Lyssavirus, e transmitida principalmente a partir da inoculação viral via saliva de um animal infectado (Swanepoel 2004). Duas variantes do vírus são descritas no Brasil, uma associada ao ciclo selvagem, isolada de bovinos e morcegos, e outra associada ao ciclo urbano, isolada de cães, gatos e humanos (Ito et al. 2001, Heinemann et al. 2002). A raiva urbana está controlada no Rio Grande do Sul desde o início da 
década de 1980, mas ainda é endêmica em várias regiões do país (Belotto et al. 2005). A raiva selvagem, no entanto, é endêmica no rebanho bovino do Estado, onde se constitui como doença neurológica viral de bovinos de maior prevalência (Sanches et al. 2000, Silva et al. 2006), com maior incidência de casos na primavera e verão (Rech et al. 2006a). Apesar de ser uma doença comumente diagnosticada em bovinos, a raiva é rara em ovinos, o que torna difícil o reconhecimento de suas características nessa espécie (Riet-Correa et al. 1983, Lima et al. 2005).

O objetivo deste trabalho é descrever os achados epidemiológicos, clínicos e patológicos de um surto de raiva em ovinos ocorrido em uma propriedade rural da região Central do Rio Grande do Sul em 2003 e demonstrar a eficiência do teste de imuno-histoquímica (IHQ) como ferramenta adicional no diagnóstico da raiva.

\section{MATERIAL E MÉTODOS}

Dados epidemiológicos e clínicos do surto foram obtidos junto ao proprietário e ao clínico encarregado dos casos. Os ovinos eram mestiços e foram designados como A e B. O Ovino A era um macho de três meses de idade e o Ovino $B$ era uma fêmea de 2,5 anos de idade. Ambos foram submetidos à eutanásia in extremis e necropsiados. Fragmentos de vários órgãos incluindo os encéfalos inteiros e a medula espinhal foram colhidos dos dois ovinos. Um monobloco composto pelo gânglio de Gasser, rete mirabile carotídea e hipófise (GRH) foi colhido do Ovino A. Todo o material foi fixado em formol a $10 \%$. O exame macroscópico do encéfalo fixado foi realizado em seções transversais feitas em intervalos de $1 \mathrm{~cm}$ após a fixação. Os cortes selecionados para histopatologia foram os mesmos recomendados para o exame do sistema nervoso central de bovinos (Barros \& Marques 2002): (1) bulbo na altura do óbex; (2) ponte na altura dos pedúnculos cerebelares; (3) cerebelo; (4) mesencéfalo na altura dos colículos rostrais; (5) telencéfalo parietal; (6) hipocampo; (7) tálamo; (8) telencéfalo frontal; (9) núcleos basais; (10) medula espinhal cervical; (11) medula espinhal torácica; e (12) medula espinhal lombar. O material foi processado rotineiramente para histologia e corado pela hematoxilina-eosina (HE). Seções de bulbo e ponte dos dois animais foram cortadas a $4 \mu \mathrm{m}$ e submetidas à IHQ em lâminas com carga elétrica, utilizando anticorpo policlonal antiribonucleoproteína (rabies polyclonal DFA reagent, Chemicon® International) na diluição de 1:1000.

\section{RESULTADOS}

A doença ocorreu em novembro de 2003 e os dois ovinos afetados desenvolveram sinais clínicos caracterizados por incoordenação, principalmente nos membros pélvicos, tremores musculares, decúbito lateral, convulsões e opistótono. O Ovino A apresentava temperatura corporal de $41^{\circ} \mathrm{C} \mathrm{e}$ o Ovino $\mathrm{B}$, de $43^{\circ} \mathrm{C}$. A evolução da doença foi de cinco dias. Numa propriedade vizinha três bovinos apresentaram sinais clínicos semelhantes e foi realizado diagnóstico histopatológico de raiva, que foi confirmado pela imunofluorescência direta (IFD) (Rech et al. 2006a). Não foram observadas alterações macroscópicas em nenhum dos ovinos. Histologicamente havia mielomeningoencefalite não-supurativa associada a inclusões eosinofílicas intracitoplasmáticas (corpús- culos de Negri) em neurônios. A intensidade das lesões variou dependendo da seção examinada. O Ovino A apresentou ganglionite e neuroipofisite não-supurativa, com variados graus de cromatólise neuronal, neuronofagia e formação de nódulos de Babes. Uma descrição mais detalhada dos sinais clínicos e achados histopatológicos pode ser observada no Quadro 1 e nas Fig.1-11.

\section{DISCUSSÃO}

A raiva é uma doença rara em ovinos no Brasil (Riet-Correa et al. 1983, Lima et al. 2005) e no restante das Américas (Belotto et al. 2005). Os casos descritos aqui foram os únicos diagnosticados pelo Laboratório de Patologia Veterinária (LPV) da Universidade Federal de Santa Maria (UFSM) em 43 anos. O motivo pelo qual a raiva é uma doença rara em ovinos em uma região endêmica para a raiva bovina não é bem compreendido. No entanto, três fatores poderiam ser considerados: (1) o controle da raiva urbana no Estado desde a década de 1980 diminuiu a possibilidade de um ovino ser atacado por um cão infectado e desenvolver a doença, (2) morcegos parecem atacar ovinos com menor freqüência (Lima et al. 2005) e preferem atacar bovinos a outros animais (Baer 1991), e (3) a espessa cobertura de lã pode dificultar e até mesmo impedir a chegada e a ação dos morcegos hematófagos em um rebanho ovino.

Devido à raridade dessa doença, o diagnóstico nestes casos foi baseado nos achados histopatológicos e confirmado pela IHQ, pois a suspeita de raiva não havia sido levantada durante o acompanhamento clínico dos animais. Esse incidente indica que a raiva sempre deve ser incluída no diagnóstico diferencial das doenças do sistema nervoso central (SNC) de ovinos, mesmo que raramente descrita nessa espécie.

O surto de raiva aqui descrito apresentou características epidemiológicas e clinicopatológicas semelhantes às observadas em surtos de raiva bovina diagnosticados na área de abrangência do LPV-UFSM (Rech et al. 2006). A doença ocorreu no final da primavera e o quadro clínico era característico da forma paralítica da doença, com alterações na locomoção e que rapidamente evoluíam para decúbito e morte. A epidemiologia da raiva varia de acordo com a área geográfica. Em áreas endêmicas o vírus é mantido em um ciclo urbano, tendo como reservatórios cães e gatos, e/ou em um ciclo selvagem, onde os reservatórios variam dependendo da região (Ito et al. 2001, Woldehiwet 2002). Na América do Sul, a raiva selvagem é transmitida pela mordedura de morcegos hematófagos, principalmente Desmodus rotunduns (Arelliano-Sota 1988, Baer 1991). Os casos descritos no presente trabalho ocorreram em uma área endêmica para raiva bovina (Rech et al. 2006a) e em meio a um surto de raiva bovina. Além disso, os sinais clínicos desenvolvidos pelos ovinos necropsiados eram semelhantes aos observados nos bovinos afetados. Essas duas características indicam que provavelmente houve o envolvimento de um mesmo vírus ou de um mesmo grupo de vírus nos surtos de raiva ovina e bovina e que o agente era mantido naquela região pela população de morcegos 
Quadro 1. Dados histopatológicos dos casos de raiva em ovinos na região Central do Rio Grande do Sul

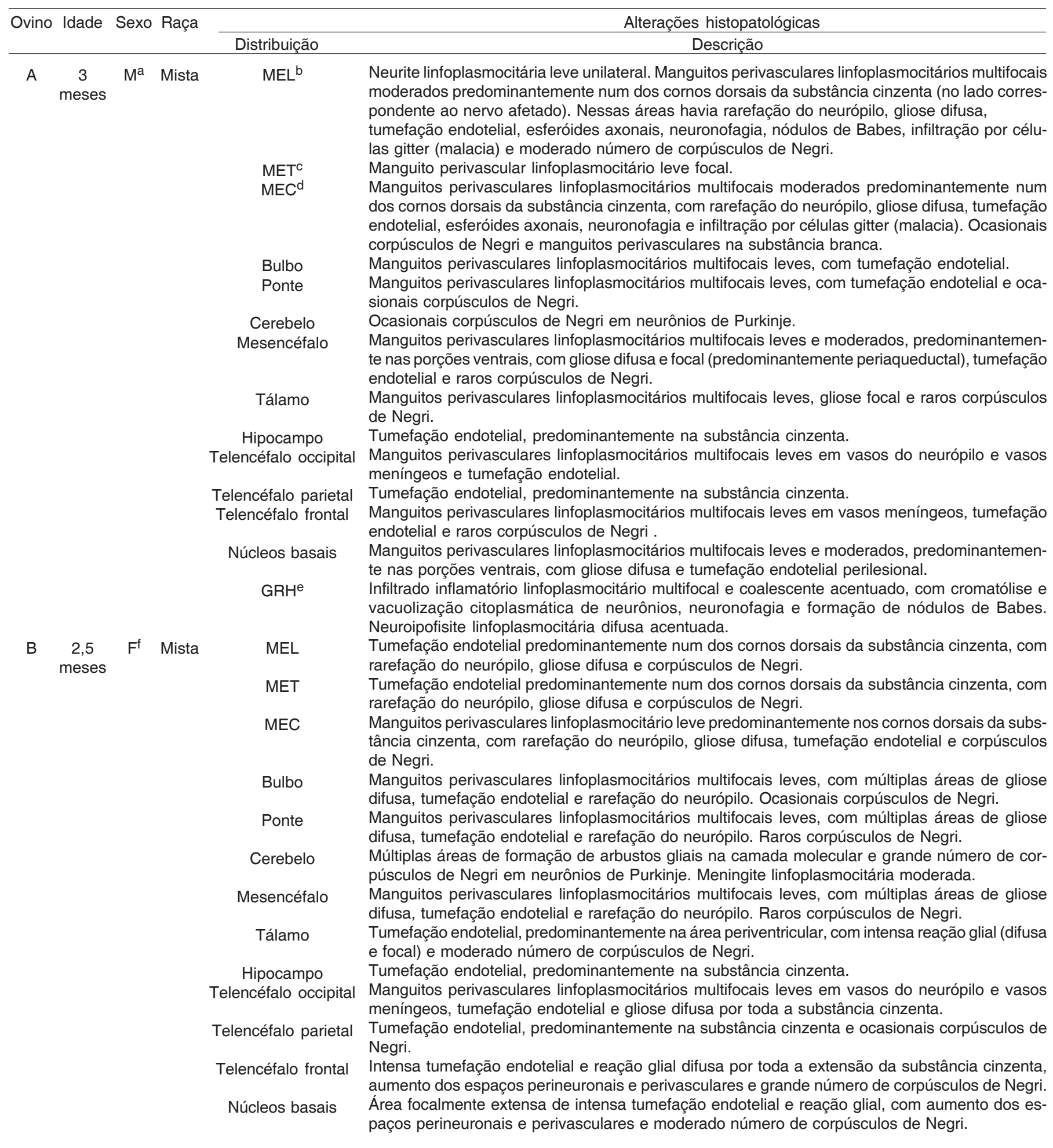

\footnotetext{
${ }^{a}$ Macho; ${ }^{b}$ medula espinhal lombar; ${ }^{c}$ medula espinhal torácica; ${ }^{d}$ medula espinhal cervical; ${ }^{e}$ gânglio de Gasser + rete mirabile carotídea + hipófise; ffêmea.
} hematófagos, que foram considerados como fonte de in-
fecção para ambas as espécies.

Estudos moleculares de amostras virais de diferentes espécies afetadas pela raiva indicam que no Brasil existem dois diferentes grupos virais que são mantidos, independentemente, por morcegos hematófagos e cães (Ito et al. 2001). Cada grupo viral está adaptado a um determinado hospedeiro e pode causar diferentes padrões clínicos quando trans- 
mitido de morcegos para ruminantes (raiva paralítica), como foi observado neste caso, ou de cães para ruminantes (raiva furiosa), como foi observado em casos de raiva ovina diagnosticados no Sul do Estado (Riet-Correa et al. 1983). Na- quela ocasião os ovinos desenvolveram alterações do comportamento, agressão, investidas contra objetos e convulsões, um quadro bastante diferente do observado nos ovinos deste relato. Além da origem do vírus (morcego ou cão),
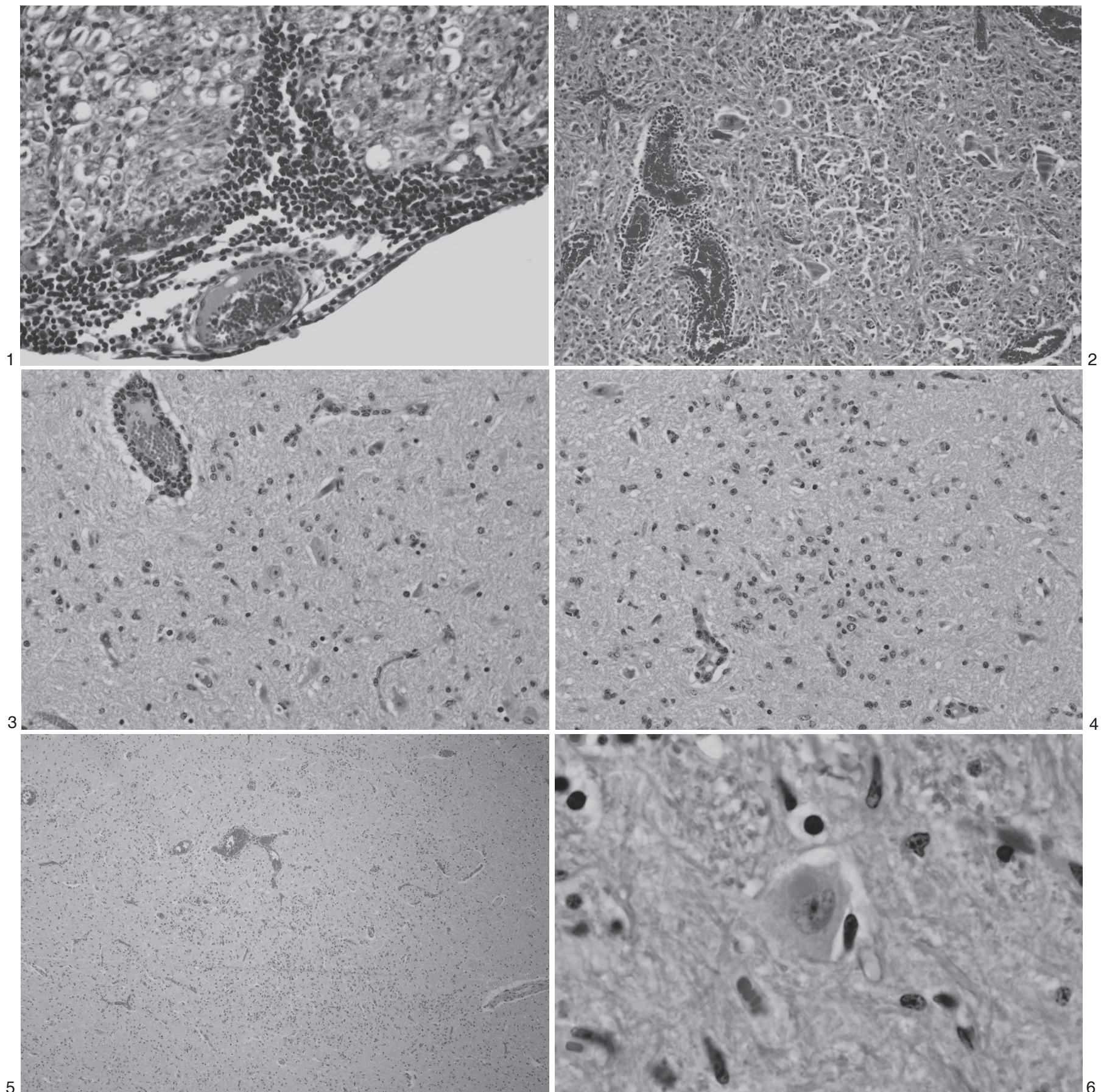

Fig.1. Raiva em ovinos (Ovino A). Perineurite linfoplasmocitária em nervo da raiz dorsal da medula espinhal lombar. HE, obj.40x.

Fig.3. Manguitos perivasculares linfoplasmocitários no tálamo; há tumefação endotelial e múltiplos corpúsculos de Negri em neurônios (Ovino A). HE, obj.20x.

Fig.5. Raiva em ovinos (Ovino B). Gliose difusa na ponte. HE, obj.20x.

Pesq. Vet. Bras. 28(10):495-500, outubro 2008

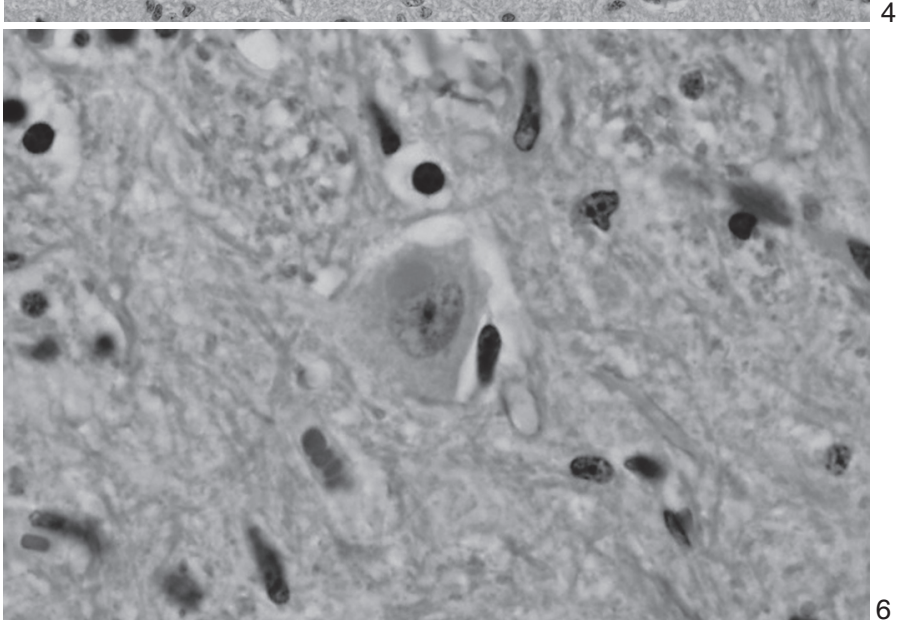

Fig.2. Infiltrado inflamatório linfoplasmocitário na medula espinhal lombar; há tumefação endotelial, formação de esferóides axonais e acentuada infiltração por células Gitter no neurópilo (Ovino A). HE, obj.20x.

Fig.4. Gliose focal na ponte (Ovino A). HE, obj.20x.

Fig.6. Corpúsculo de Negri em neurônio do tálamo (Ovino B). HE, obj.100x. 
as características da cepa viral também parecem influenciar o quadro clínico, pois ovinos infectados pela mordida de cães desenvolveram sinais da forma paralítica da doença (Lima et al. 2005) e casos experimentais de raiva em ovinos com variantes virais européias isoladas de morcegos reproduziram doença clínica com características da forma furiosa da doença (Brookes et al. 2007).

Não foram encontradas alterações macroscópicas nos dois ovinos necropsiados. Hiperemia dos vasos leptomeníngeos, distensão da bexiga e do reto e traumas auto-infligidos são possíveis achados observados em casos de raiva em herbívoros, porém nem sempre estão presentes (Lima et al. 2005, Rech et al. 2006a). Os achados

Fig.7. Proliferação focalmente extensa da micróglia (arbustos gliais) na camada molecular do cerebelo (Ovino B). HE, obj.20x.

Fig.8. Ganglionite não-supurativa; observa-se a intensa infiltração de células inflamatórias entre os neurônios do gânglio de Gasser (Ovino A). HE, obj.20x.

Fig.9. Neurônio vacuolizado (esquerda) e nódulo neuronofágico (direita) no gânglio de Gasser (Ovino A). HE, obj.100x.

Fig.10. Neuro-hipofisite (Ovino A). HE, obj.10x.

Fig.11. Neurônio da ponte com marcação positiva no teste de imuno-histoquímica (Ovino B). Avidina-biotina, obj.100x.
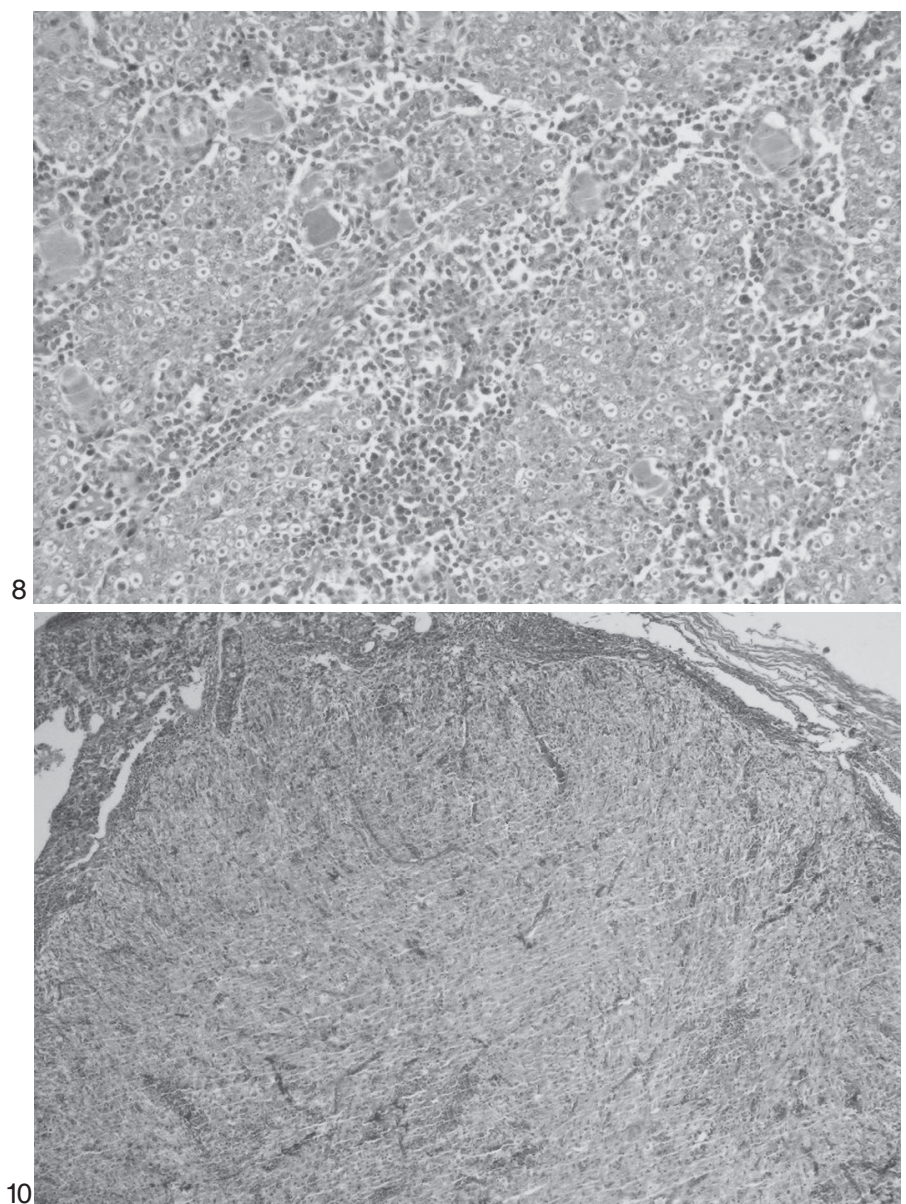

histopatológicos eram característicos de raiva e semelhantes aos observados em casos da doença em ruminantes e eqüinos (Riet-Correa et al. 1983, Langohr et al. 2003, Lima et al. 2005, Rech et al. 2006a,b, Pierezan et al. 2007). As lesões eram mais concentradas na medula espinhal, seguida do tronco encefálico e do cerebelo, e refletem a distribuição antigênica e a via de entrada do vírus no SNC (Bingham \& van der Merwe 2002, Swanepoel 2004). Após replicação primária em terminações nervosas próximas ao sítio de entrada, as partículas virais são transportadas via axônio para a medula espinhal e para o encéfalo, chegan-
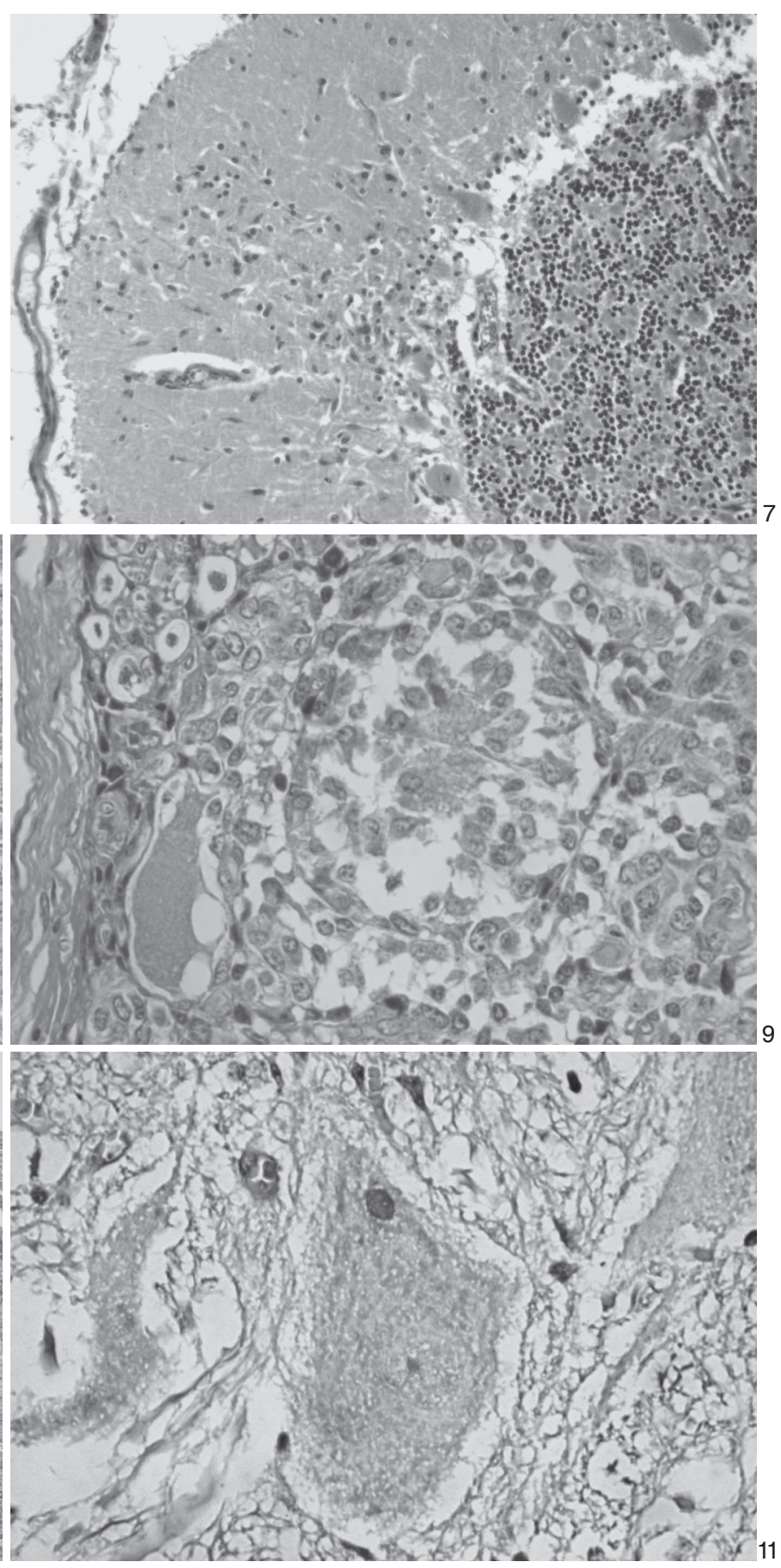
do primeiramente no tronco encefálico. A distribuição das lesões observadas no SNC destes ovinos é semelhante às descritas em casos de raiva em ruminantes no Brasil (Langohr et al. 2003, Lima et al. 2005), porém, a natureza dessas lesões foi um pouco diferente. Casos de raiva em bovinos normalmente apresentam lesões predominantemente inflamatórias e um menor grau de lesões degenerativas no tronco encefálico (Langohr et al. 2003), enquanto que eqüinos afetados pela raiva parecem desenvolver um maior grau de lesões degenerativas (Pierezan et al. 2007) e com distribuição mais difusa no SNC (Lima et al. 2005). Se forem comparadas as três espécies, os ovinos deste relato apresentaram lesões que foram observadas tanto em bovinos como em eqüinos. A quantidade de $\mathrm{CN}$ foi maior em áreas com menor grau de lesões e esse parece ser um achado constante em casos da doença (Langohr et al. 2003, Lima et al. 2005). Essas inclusões eram facilmente observadas em grandes neurônios, como os da medula espinhal, mesencéfalo e cerebelo, e variaram em número e localização neuroanatômica em cada caso.

Várias técnicas têm sido utilizadas para o diagnóstico da raiva, mas a IFD e a inoculação intracerebral em camundongos (ICC) são consideradas os testes-padrão (Swanepoel 2004). Como o diagnóstico histopatológico depende da observação de CN característicos e esse achado nem sempre está presente (Langohr et al. 2003, Rech et al. 2006a,b), o diagnóstico oficial da raiva necessita da confirmação por IFD e/ou ICC. As amostras dos casos aqui descritos não foram coletadas para testes virológicos por não ter havido suspeita clínica de raiva. No entanto, foram observados $\mathrm{CN}$ em ambos os casos e seções de ponte e bulbo foram positivas na IHQ. Essa região (tronco encefálico) foi selecionada para IHQ por ser a área de eleição para testes de marcação antigênica em bovinos (Bingham \& van der Merwe 2002). A técnica de IHQ mostrou ser específica e sensível para a confirmação do diagnóstico e vem sendo usada como ferramenta adicional no diagnóstico de raiva em humanos e animais, principalmente em casos onde há somente meningoencefalite nãosupurativa, sem CN, em casos em que as técnicas de IFD e ICC resultam negativas e na realização de estudos retrospectivos de material emblocado em parafina (Jogai et al. 2000, Vural et al. 2001, Arslan et al. 2004, Pierezan et al. 2007). Nos neurônios marcados positivamente eram observados antígenos virais distribuídos como finos grânulos dispersos pelo citoplasma ou em densos agregados circulares de 3-10 $\mu \mathrm{m}$ de diâmetro.

A baixa freqüência de diagnósticos de raiva em ovinos na nossa rotina e na de outros laboratórios do país impede a geração de dados substanciais sobre as características da doença nessa espécie. No entanto, as circunstâncias epidemiológicas (controle da raiva urbana no Estado e presença de raiva bovina endêmica transmitida por morcegos) deste surto indicam que é provável que ocasionais surtos de raiva ovina no Rio Grande do Sul sejam transmitidos por morcegos e, conseqüentemente, apresentem um padrão clinicopatológico semelhante ao de casos de raiva bovina.

\section{REFERÊNCIAS}

Arelliano-Sota C. 1988. Vampire bat-transmitted rabies in cattle. Rev. Infect. Dis. 10(4):707-709.

Arslan A., Saglam Y.S. \& Temur A. 2004. Detection of rabies viral antigen in non-autolysed and autolysed tissues by using an immunoperoxidase technique. Vet. Rec. 155:550-552.

Baer G. 1991. Vampire bat and bovine paralytic rabies, p.389-404. In: Ibid (Ed.), The natural History of Rabies. CRC, Boca Raton.

Barros C.S.L. \& Marques G.H.F. 2003. Procedimentos para o diagnóstico das doenças do sistema nervoso central de bovinos. Departamento de Defesa Animal, Ministério da Agricultura, Pecuária e Abastecimento (MAPA), Brasília. 50p. Disponível na internet: http:// www.agricultura.gov.br

Belotto A., Leanes L.F., Schneider M.C., Tamayo H. \& Correa E. 2005. Overview of rabies in the Americas. Virus Res. 111:5-12.

Bingham J. \& van der Merwe M. 2002. Distribution of rabies antigen in infected brain material: determining the reliability of different regions of the brain for the rabies fluorescent antibody test. J. Virol. Meth. 101:85-94.

Brookes S.M., Klopfleisch R., Müller T., Healy D.M., Teifke J.P., Lange E., Kliemt J., Johnson N., Johnson L., Kaden V., Vos A. \& Fooks A.R. 2007. Susceptibility of sheep to European bat lyssavirus type-1 and 2 infection: A clinical pathogenesis study. Vet. Microbiol. 125(3/4):210223.

Heinemann F.M., Fernandes-Matioli F.M.C., Cortez A., Soares R.M., Sakamoto S.M., Bernardi F., Ito F.H., Madeira A.M.B.N. \& Richtzenhain L.J. 2002. Genealogical analysis of rabies vírus strain from Brazil base don $\mathrm{N}$ gene alleles. Epidemiol. Infect. 128:503-511.

Ito M., Arai Y.T., Itou T., Sakai T., Ito F.H., Takasaki T. \& Kurane I. 2001. Genetic characterization and geographic distribution of rabies virus isolates in Brazil: Identification of two reservoirs, dogs and vampire bats. Virol. 284:214-222.

Jogai S., Radotra B.D. \& Banerjee A.K. 2000. Immunohistochemical study of human rabies. Neuropathol. 20:197-203.

Langohr I.M., Irigoyen L.F., Lemos R.A.A. \& Barros C.S.L. 2003. Aspectos epidemiológicos, clínicos e distribuição das lesões histológicas no encéfalo de bovinos com raiva. Ciência Rural 33:125-131.

Lima E.F., Riet-Correa F., Castro R.S., Gomes A.A.B. \& Lima F.S. 2005. Sinais clínicos, distribuição das lesões no sistema nervoso e epidemiologia da raiva em herbívoros na região Nordeste do Brasil. Pesq. Vet. Bras. 25(4):250-264.

Pierezan F., Lemos R.A.A., Rech R.R., Rissi D.R., Kommers G.D., Cortada V.C.L.M., Mori A.E. \& Barros C.S.L. 2007. Raiva em eqüinos. Enapave, Campo Grande, MS. (Resumo)

Rech R.R., Rissi D.R., Pierezan F., Inkelmann M.A. \& Barros C.S.L. 2006a. Raiva em herbívoros: 27 casos. Endivet, Campo Grande, MS. (Resumo)

Rech R.R., Rissi D.R., Silva M.C., Inkelmann M.A. \& Barros C.S.L. 2006b. Histomorfologia do gânglio de Gasser, da rete mirabile carotídea e da hipófise de bovinos: estudo de 199 casos. Pesq. Vet. Bras. 26:105111.

Riet-Correa F., Schild A.L., Méndez M.C., Oliveira J.A., Gil-Turnes C. \& Gonçalves A. 1983. Atividades do Laboratório Regional de Diagnóstico e doenças da área de influência no período 1978-1982. Editora Universitária, Pelotas, RS. 98p.

Swanepoel R. 2004. Rabies, p.1123-1182. In: Coetzer J.A.W. \& Tustin R.C. (Ed.), Infectious diseases of livestock. Vol.2. Oxford University Press, Cape Town.

Silva M.C., Rissi D.R., Fighera R.A. \& Barros C.S.L. 2006. Diagnósticos realizados pelo Laboratório de Patologia Veterinária da Universidade Federal de Santa Maria em bovinos necropsiados entre 1964 e 2005. Endivet, Campo Grande, MS. (Resumo)

Woldehiwet Z. 2002. Rabies: recent developments. Res. Vet. Sci. 73:1725. 